\title{
Characterization of Soil Water Content Variability and Soil Texture using GPR Groundwave Techniques
}

\author{
Katherine Grote ${ }^{1}$, Cale Anger ${ }^{2}$, Bridget Kelly ${ }^{3}$, Susan Hubbard ${ }^{4}$ and Yoram Rubin ${ }^{5}$ \\ ${ }^{1}$ Department of Geology, University of Wisconsin - Eau Claire, Eau Claire, WI 54702 \\ Email: grotekr@uwec.edu \\ ${ }^{2}$ Department of Geology and Geophysics, University of Minnesota, Minneapolis, MN 55455 \\ Email: ange0075@umn.edu \\ ${ }^{3}$ Department of Geosciences, University of Nebraska - Lincoln, Lincoln, NE 68588 \\ Email: bridget_kelly@gmail.com \\ ${ }^{4}$ Geophysics Department, Lawrence Berkeley National Laboratory, Berkeley, CA 94720 \\ Email: sshubbard@lbl.gov (Note: Hubbard's contribution is supported as part of the Subsurface Science \\ Scientific Focus Area funded by the U.S. Department of Energy, Office of Science, Office of \\ Biological and Environmental Research under Award Number DE-AC02-05CH11231.) \\ ${ }^{5}$ Civil and Environmental Engineering, University of California - Berkeley, Berkeley, CA 94720-1710 \\ Email: rubin@ce.berkeley.edu
}

\begin{abstract}
Accurate characterization of near-surface soil water content is vital for guiding agricultural management decisions and for reducing the potential negative environmental impacts of agriculture. Characterizing the near-surface soil water content can be difficult, as this parameter is often both spatially and temporally variable, and obtaining sufficient measurements to describe the heterogeneity can be prohibitively expensive. Understanding the spatial correlation of near-surface soil water content can help optimize data acquisition and improve understanding of the processes controlling soil water content at the field scale. In this study, ground penetrating radar (GPR) methods were used to characterize the spatial correlation of water content in a three acre field as a function of sampling depth, season, vegetation, and soil texture. GPR data were acquired with $450 \mathrm{MHz}$ and $900 \mathrm{MHz}$ antennas, and measurements of the GPR groundwave were used to estimate soil water content at four different times. Additional water content estimates were obtained using time domain reflectometry measurements, and soil texture measurements were also acquired. Variograms were calculated for each set of measurements, and comparison of these variograms showed that the horizontal spatial correlation was greater for deeper water content measurements than for shallower measurements. Precipitation and irrigation were both shown to increase the spatial variability of water content, while shallowly-rooted vegetation decreased the variability. Comparison of the variograms of water content and soil texture showed that soil texture generally had greater small-scale spatial correlation than water content, and that the variability of water content in deeper soil layers was more closely correlated to soil texture than were shallower water content measurements. Lastly, cross-variograms of soil texture and water content were calculated, and co-kriging of water content estimates and soil texture measurements showed that geophysically-derived estimates of soil water content could be used to improve spatial estimation of soil texture.
\end{abstract}

\section{Introduction}

Accurate estimates of soil water content are important for maximizing crop yield, efficiently applying irrigation, and minimizing the potential environmental impacts of farming. Crop yield is partially influenced by soil water content; crop yield will decrease if the soil water content is below a crop-specific range (van Wijk, 1988; Williams et al., 1990; Dry et al., 2000). Crop yield is also affected by fertilization, and the soil must have a favorable water content to allow plants to fully absorb the nutrients in fertilizers and to achieve high nutrient efficiency (Fageria, 1992). Thus, crop yield can be maximized and nutrients can be applied most efficiently when the soil water content is well characterized across a field. In addition to crop yield, the quality 
of some crops, such as wine grapes, partially depends on soil water content, so this parameter is regulated to ensure that it remains in the appropriate range. Monitoring of the soil water content is also needed to ensure efficient use of irrigation water, where the scheduling and volume of irrigation must be optimized to appropriately allocate limited water supplies. Finally, knowledge of the soil water content can help farmers reduce the potential negative environmental impacts of agriculture such as salinization or groundwater degradation (when excess irrigation carries fertilizers, pesticides, and salts into the saturated zone) (Rangeley, 1987).

The spatial and temporal variability of the nearsurface soil water content has been well documented at a range of scales and using several different methods of measurement. Measurements of water content have been acquired at scales ranging from a single field to several hectares using gravimetric sampling, time domain reflectometry (TDR), capacitance sensors, and neutron probes (Bouten et al., 1992; Grayson et al., 1997; Famiglietti et al., 1998; Western et al., 1998; Western et al., 1999; Petrone et al., 2004; De Lannoy et al., 2006). Some studies have used estimates of soil water content from remote sensing methods to explore water content variability on a larger scale (Vischel et al., 2008), while other researchers have used data simultaneously acquired from ground-based and remote sensing techniques (Famiglietti et al., 1999; Bosch et al., 2006; Famiglietti et al., 2008). Vertical measurements of soil water content have also been acquired to observe the changes in water content variability with depth (Hupet and Vanclooster, 2002; Bosch et al., 2006; De Lannoy et al., 2006). Collectively, the many studies of soil water content variability have shown that near-surface soil moisture is a function of spatially and sometimes temporally variable properties such as soil texture, soil depth, topography, vegetation, precipitation, evapotranspiration, and agricultural practices.

The variability of soil water content makes accurate characterization of this parameter difficult at large scales (Western and Blöschl, 1999). Conventional techniques for monitoring the soil water content (i.e., gravimetric sampling, neutron probes, TDR, capacitance probes, and tensiometers) are point measurements, and it is often prohibitively expensive to collect sufficient measurements to accurately image the water content at large scales (Hillel, 1997; Vischel et al., 2008). An alternative to conventional techniques is microwave remote sensing methods, which can rapidly acquire estimates of water content in the uppermost $0-5 \mathrm{~cm}$ of the subsurface over large areas (Famiglietti et al., 2008). However, remote sensing techniques cannot provide water content estimates if significant vegetation is

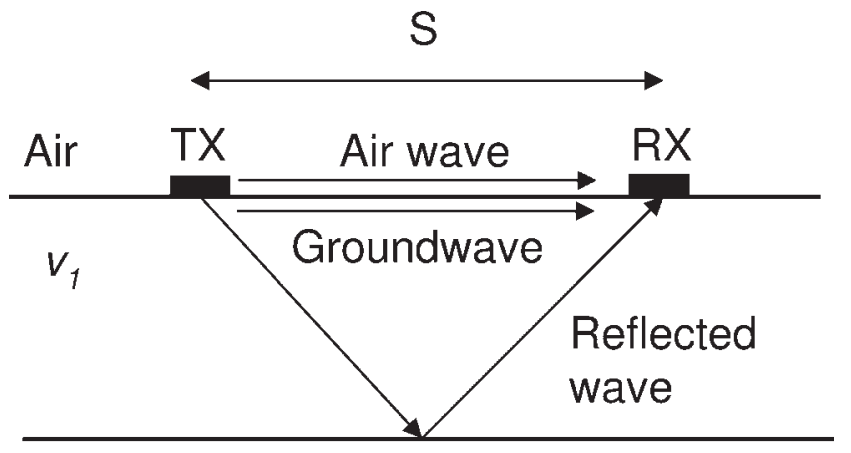

$V_{2}$

Figure 1. The GPR groundwave travels in the shallow subsurface between the transmitting antenna (TX) and receiving antenna $(\mathrm{RX}) . \mathrm{S}$ is the separation distance between the GPR antennas, while $v_{1}$ is the velocity of the uppermost soil layer.

present (Famiglietti et al., 1999), and the resolution of remote sensing estimates is typically between tens of meters to $50 \mathrm{~km}$ (Vischel et al., 2008). Also, remote sensing data often require ground truth measurements of water content for calibration and validation (Famiglietti et al., 1999).

An alternative to both conventional point measurement techniques and remote sensing is soil water content estimation using non-invasive geophysical techniques such as ground penetrating radar (GPR). GPR is a high-frequency electromagnetic technique that has been used to acquire accurate estimates of soil water content at a variety of scales (Huisman et al., 2003). GPR groundwaves are especially useful for rapidly acquiring very high-resolution estimates of soil water content in the shallow subsurface over large areas (Lesmes et al., 1999; Huisman et al., 2001; Hubbard et al., 2002; Galagedara et al., 2003; Grote et al., 2003; Huisman et al., 2003; Galagedara et al., 2004; Galagedara et al., 2005a; Hubbard et al., 2006). As shown in Fig. 1, groundwaves are boundary waves that are confined to the air-ground interface and travel directly between the transmitting and receiving antennas in the near subsurface (van Overmeeren et al., 1997; Berktold et al., 1998). The GPR groundwave travels at the velocity of an electromagnetic wave in the near-surface soil, and the groundwave velocity can be determined by measuring the separation distance between the transmitting and receiving antennas and recording the time needed for the groundwave to travel between the antennas (Huisman et al., 2003; Galagedera et al., 2005a; Hubbard et al., 2006). The electromagnetic velocity is primarily influenced by the soil water content (Davis and Annan, 1989), and the velocity can be related 

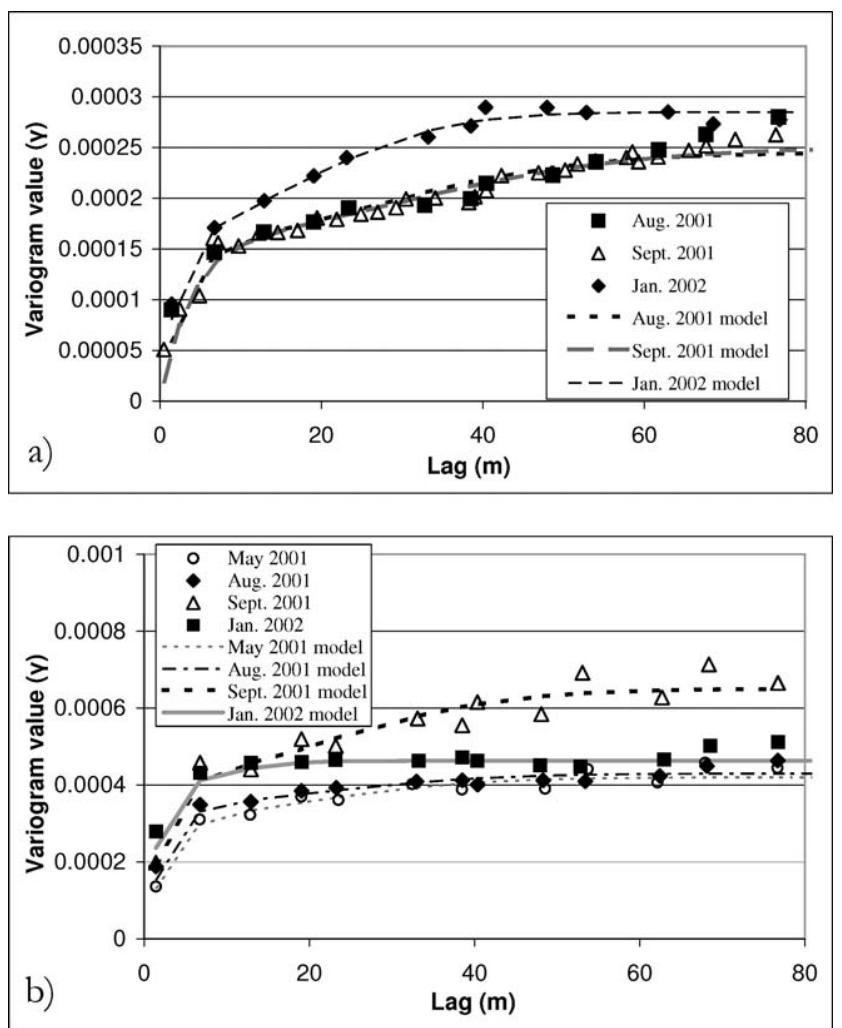

Figure 7. a) Experimental variograms and variogram models for water content estimates from $450 \mathrm{MHz}$ GPR data. b) Experimental variograms and variogram models for water content estimates from $900 \mathrm{MHz}$ GPR data.

irrigation, while lateral redistribution of soil water (largely controlled by soil texture at this site) may reduce the effects of these processes on the deeper water content measurements. The water content in deeper soil is also less affected by diurnal variations in temperature and evapotranspiration.

Although the shallower sampling depth of the $900 \mathrm{MHz}$ data may explain the higher variability observed in this data set, it is important to note that the sample volume for the $900 \mathrm{MHz}$ data is smaller than that of the $450 \mathrm{MHz}$ data. The sample volume is approximately the antenna separation multiplied by the sampling depth, and the antenna separations for the $900 \mathrm{MHz}$ and $450 \mathrm{MHz}$ data are $17 \mathrm{~cm}$ and $25 \mathrm{~cm}$, respectively. Thus, the $900 \mathrm{MHz}$ antennas have a smaller lateral sampling distance as well as a probable shallower sampling depth. The larger sample volume of the $450 \mathrm{MHz}$ data is expected to result in reduced variability, so the difference in variability between the two frequencies could be caused by the different sample volumes rather than by different sampling depths. Although the sample volume probably influences the water content variability, analysis of the water content estimates from TDR data acquired in Jan. 2002 indicate that sampling depth probably has a greater impact on water content variability than does sample volume at this site. The TDR probes are $15 \mathrm{~cm}$ long, so the sampling depth of the TDR is similar to the estimated sampling depth of the $450 \mathrm{MHz}$ GPR data. However, the sample volume for the TDR probes is much less, as the two TDR prongs are separated by only $5 \mathrm{~cm}$, and the area between and immediately adjacent to the prongs has the greatest influence on the TDR response (Topp et al., 1996). Estimates of soil water content obtained from the TDR data and the $450 \mathrm{MHz}$ GPR data are very similar, and the experimental variogram of water content estimated from TDR data shows variability between that of the $450 \mathrm{MHz}$ and $900 \mathrm{MHz}$ GPR data, as shown in Fig. 6(a). If each of these variograms is normalized by the variance of the water content estimates, the variograms from the $450 \mathrm{MHz}$ GPR and TDR data are very similar, while the variogram from the $900 \mathrm{MHz}$ data shows less spatial correlation (Fig. 6(b)). Since the TDR data have a sampling depth that is similar to the estimated sampling depth of the $450 \mathrm{MHz}$ data, these results indicate that variability decreases with depth regardless of sample volume.

The decrease in variability with depth observed in this experiment was similar to the findings of other researchers. Hupet and Vanclooster (2002) found that total variability decreased with depth, with the greatest variability occurring in their shallowest sampling interval $(0$ to $20 \mathrm{~cm})$. They calculated variograms from water content measurements acquired at different times and depths, and they found that for soil water content measured in intervals from the surface to $75-\mathrm{cm}$ depth, the variograms showed no spatial correlation (pure nugget model). Variograms for water content measurements at $100-\mathrm{cm}$ and $125-\mathrm{cm}$ depth showed the expected trend of the variogram values increasing with lag. The authors attributed the lack of spatial correlation in the shallower soils to the effects of vegetation at the site, where vegetation was believed to be the primary factor controlling soil moisture patterns. The authors noted that spatial correlations of shallow water content might exist at smaller lags than those investigated in this project (minimum lag was $\sim 15 \mathrm{~m}$ ). In another study, Bosch et al. (2006) used much shallower samples, but also found that the total variability of the soil at 0 to $3 \mathrm{~cm}$ depth was greater than that at 3 to $6 \mathrm{~cm}$ depth. These authors attributed the increased variability at shallow depths to changes in soil texture and microtopography. In contrast, De Lannoy et al. (2006) collected deeper water content measurements (at approximately $30 \mathrm{~cm}$ intervals to a depth of $180 \mathrm{~cm}$ ) and found that spatial variability generally increased with depth; the changes in variability with depth were attributed to changes in the hydraulic properties of soils 
Table 1. Means and standard deviations of volumetric water content for estimates derived from $450 \mathrm{MHz}$ and $900 \mathrm{MHz}$ GPR data in rows with and without crop cover for each data campaign. $450 \mathrm{MHz}$ data were not acquired in May 2001.

\begin{tabular}{|c|c|c|c|c|c|}
\hline Campaign & $\begin{array}{c}\text { Central } \\
\text { frequency }(\mathrm{MHz})\end{array}$ & $\begin{array}{l}\text { Mean water } \\
\text { content in rows } \\
\text { with crop cover }\end{array}$ & $\begin{array}{c}\text { Mean water } \\
\text { content in rows } \\
\text { without crop cover }\end{array}$ & $\begin{array}{l}\text { Standard deviation } \\
\text { of water content in } \\
\text { rows with crop cover }\end{array}$ & $\begin{array}{l}\text { Standard deviation of } \\
\text { water content in rows } \\
\text { without crop cover }\end{array}$ \\
\hline May 2001 & 900 & 0.108 & 0.118 & 0.012 & 0.017 \\
\hline August 2001 & 450 & 0.095 & 0.095 & 0.010 & 0.013 \\
\hline August 2001 & 900 & 0.082 & 0.090 & 0.015 & 0.016 \\
\hline September 2001 & 450 & 0.145 & 0.150 & 0.010 & 0.012 \\
\hline September 2001 & 900 & 0.104 & 0.117 & 0.013 & 0.020 \\
\hline January 2002 & 450 & 0.248 & 0.250 & 0.013 & 0.014 \\
\hline January 2002 & 900 & 0.247 & 0.247 & 0.018 & 0.016 \\
\hline
\end{tabular}

across the site. The deeper measurements acquired by De Lannoy et al. (2006) might have been less influenced by surficial processes than the shallower measurements acquired in other studies.

\section{Water Content Variability and Seasonal Water}

\section{Content Fluctuations}

Many studies have shown that water content variability changes as a function of the mean soil water content, although a clear relationship between the variability and the mean has not been defined. In some studies, the spatial variability of near-surface water content was found to be greater in drier soils (Famiglietti et al., 1999; Hupet and Vanclooster, 2002; Bosch et al., 2006), while other studies showed variability to be greater in wetter soils (Bell et al., 1980; Famiglietti et al., 1998). De Lannoy et al. (2006) observed that the relationship between soil water content variability and the mean water content changed with depth, where shallower measurements (uppermost $10 \mathrm{~cm}$ ) exhibited greater spatial variability at higher moisture contents, while deeper measurements (50 $\mathrm{cm}$ and below) showed variability increasing at lower moisture contents. Owe et al. (1982) and Famiglietti et al. (2008) observed maximum near-surface water content variability in moderately wet soils, with decreased variability in both dry and very wet soils. Peters-Lidard and Pan (2002) suggested that these observations can be explained by soil texture heterogeneity, where soil moisture variability increases as the soil dries out if the mean soil water content is between the field capacity of the soil and full saturation (the soil is initially very wet), but the variability will decrease with drying if the water content is initially less than the field capacity of the soil.

Other studies of water content variability have considered variograms calculated using water content measurements in wet and in dry soils. Western et al. (1998) found that less correlation was observed in wet soil (higher sills and correlation lengths of $35 \mathrm{~m}$ to $50 \mathrm{~m}$ ) than in drier soil (lower sills and correlation lengths of $50 \mathrm{~m}$ to $60 \mathrm{~m}$ ). The changes in the variograms with mean soil moisture are attributed to lateral redistribution of water during different seasons. When the soil was dry, the soil moisture distribution was relatively uniform (lower sill), because the hydraulic properties of the soil were limiting evapotranspiration (soil properties were assumed to be the main factor controlling soil moisture patterns), and lateral redistribution of water was less significant. When the soil was wet, lateral redistribution of water content caused by topographic variations contributed to higher variability. In another study, De Lannoy et al. (2006) observed variability that partially follows the pattern described by Western et al. (1998). De Lannoy et al. observed that for shallow water content measurements (uppermost $10 \mathrm{~cm}$ ), the variogram range and sill both increase with increasing soil moisture (range varies from $200 \mathrm{~m}$ to over $300 \mathrm{~m}$ ) and decrease during dry periods. When the soil was very dry, the variogram shape was best fit by a pure nugget model, suggesting that either there was very little spatial structure of water content under these conditions or that the measurement error was greater than the spatial variability of water content.

The results of this experiment are different from those in both of the variogram studies described above. In this study, GPR data acquired at four different times were used to calculate variograms of soil water content. The May (when only $900 \mathrm{MHz}$ data were collected) and Aug. data sets were acquired during the dry season, and no irrigation or precipitation had occurred for at least a week prior to data acquisition; the soil water content was quite low during these data acquisition campaigns (Table 1). The Sept. data set was acquired two days after drip irrigation was applied at the base of each grapevine, creating a wet zone in the soil immediately surrounding the vine. January data were acquired during the wet winter, and light precipitation occurred the day prior to data acquisition. The experimental 
Table 2. Variogram model parameters for each campaign. In each entry, a linear combination of an exponential model (E) and Gaussian model (G) was used. The first parameter listed after the letter representing the model type is the sill for that model, while the second parameter is the correlation length.

\begin{tabular}{|c|c|c|c|c|}
\hline Campaign & $\begin{array}{c}\text { Central } \\
\text { Frequency }(\mathrm{MHz})\end{array}$ & All rows & Rows without crop cover & Rows with crop cover \\
\hline \multirow[t]{2}{*}{ May 2001} & 900 & E, $0.000316,6.5$ & E, $0.0004,12$ & E, $0.0002,15$ \\
\hline & & $\mathrm{G}, 0.00042,40$ & $G, 0.000485,39$ & $\mathrm{G}, 0.0003,85$ \\
\hline \multirow[t]{2}{*}{ August 2001} & 900 & E, $0.000348,6$ & E, $0.00037,9.5$ & E, $0.00028,9.5$ \\
\hline & & $G, 0.00043,42$ & $\mathrm{G}, 0.00043,30$ & $\mathrm{G}, 0.00047,55$ \\
\hline \multirow[t]{2}{*}{ August 2001} & 450 & $\mathrm{E}, 0.000156,9$ & $\mathrm{E}, 0.0002,15$ & E, $0.00011,4$ \\
\hline & & $\mathrm{G}, 0.000245,63$ & $\mathrm{G}, 0.00033,55$ & $\mathrm{G}, 0.000215,95$ \\
\hline \multirow[t]{2}{*}{ September 2001} & 900 & $\mathrm{E}, 0.00042,7$ & E, $0.00042,4$ & E, $0.00021,9$ \\
\hline & & $\mathrm{G}, 0.00065,53$ & $\mathrm{G}, 0.00078,58$ & $G, 0.00031,43$ \\
\hline \multirow[t]{2}{*}{ September 2001} & 450 & E, $0.00016,9.5$ & $\mathrm{E}, 0.0001,8.6$ & E, $0.0001,7.6$ \\
\hline & & $\mathrm{G}, 0.00025,59$ & $\mathrm{G}, 0.000245,35$ & $\mathrm{G}, 0.00019,54$ \\
\hline \multirow[t]{2}{*}{ January 2002} & 900 & E, $0.000401,4$ & E, $0.00041,8$ & E, $0.0004,6$ \\
\hline & & $\mathrm{G}, 0.000463,17$ & $\mathrm{G}, 0.00045,20$ & $\mathrm{G}, 0.00051,25$ \\
\hline \multirow[t]{2}{*}{ January 2002} & 450 & E, $0.00017,6.7$ & $\mathrm{E}, 0.0002,10$ & E, $0.00018,6$ \\
\hline & & $\mathrm{G}, 0.000285,42.5$ & $\mathrm{G}, 0.00033,50$ & $\mathrm{G}, 0.00025,38$ \\
\hline
\end{tabular}

variograms of water content for each of these data acquisition campaigns are shown in Fig. 7(a) for the $450 \mathrm{MHz}$ data and Fig. 7(b) for the $900 \mathrm{MHz}$ data. For the $450 \mathrm{MHz}$ data, the variograms for the Aug. and Sept. data sets are very similar, indicating that the spatial correlation of water content may be temporally stable in dry soils. The sills for the drier campaigns (Aug. and Sept.) are not reached in the experimental variograms, but the variances of all three data sets are similar. The estimated ranges of the variograms calculated from the Aug. and Sept. data sets $(\sim 100 \mathrm{~m})$ are considerably higher than the range of the variogram calculated from wet soil in Jan. $(\sim 70 \mathrm{~m})$. The relatively small range observed in the wetter soil may reflect different rates of evaporation or infiltration as a function of soil texture or may indicate variations in porosity. (During the dry season, the soil may have already lost enough moisture that evapotranspiration was limited, and GPR techniques are not well suited to detect variations in porosity in more uniformly dry soils.) Factors other than soil texture are less likely to be significant at this site, since topography is negligible and agricultural practices are uniform across the site.

A slightly different pattern of variability is observed in the water content estimates obtained from the $900 \mathrm{MHz}$ GPR data. For these data, the estimates obtained in Sept. had the highest sill and the longest range $(\sim 90 \mathrm{~m})$. The high sill observed in Sept. may be caused by drip irrigation, which created wet zones immediately adjacent to the vines and therefore in- creased the total water content heterogeneity. The effects of drip irrigation on near-surface water content appear to be very shallow, since the $900 \mathrm{MHz}$ water content estimates were significantly influenced by the additional moisture, but the deeper $450 \mathrm{MHz}$ estimates were not. Except for the unusually high variability of the $900 \mathrm{MHz}$ Sept. data, the $450 \mathrm{MHz}$ and $900 \mathrm{MHz}$ data show similar trends for spatial correlation. The variograms from the $900 \mathrm{MHz}$ data acquired in Jan. again have similar sills to variograms calculated from May and Aug. data, and the range of the Jan. data $(\sim 30 \mathrm{~m})$ is less than the ranges of the drier data sets $(\sim 80 \mathrm{~m})$. A comparison of the $900 \mathrm{MHz}$ variograms from Sept. and Jan. indicates that both irrigation and precipitation increase water content variability, but the variability caused by precipitation that is relatively evenly distributed across the field is less than the variability caused by irrigation applied immediately adjacent to each vine.

If the seasonal variability observed at the Mondavi site is interpreted using the explanation of Peters-Lidard and Pan (2002), the relatively high variability of the wet Jan. soil could indicate that the soil was between the field capacity and full saturation, but closer to field capacity. This seems likely, as the mean water content in Jan. was high. The explanation also seems to describe the drier data sets (May and Aug.), since it seems likely that the mean water contents at these times were already below field capacity, and thus lower variability would be expected with increased drying. 
the effects of vegetation observed by other researchers.

\section{Vegetation}

The effects of transpiration on mean soil water content are well documented, but the influence of vegetation on water content variability is not clear. Hupet and Vanclooster (2002) calculated variograms from water content measurements acquired in a field of maize. Analysis of these variograms showed little spatial correlation of water content at shallow depths, and the authors attributed the high spatial variability of shallow water content to the spatially variable vegetation, and thus variable root water uptake and evapotranspiration across the field. De Lannoy et al. (2006) also noted that the high water content variability they observed in wet, shallow soils may be partially caused by vegetation which causes variable interception of precipitation. Wilson et al. (2004) noted that vegetation was probably responsible for some of the water content heterogeneity that was not explained by topographic effects. Or and Rubin (1993) performed a modeling study that showed that the spatial distribution of water content was greatly influenced by the behavior of shallow vegetation, even at depths extending below the root zone.

At the Mondavi site, near-surface vegetation appears to affect both the mean and the variability of soil water content. The water content distribution in Fig. 3 exhibits a striped pattern, where adjacent traverses sometimes have significantly different water contents. The traverses were separated by $6 \mathrm{~m}$, and considerable differences in water content between adjacent traverses caused by soil heterogeneity over this distance is possible, but would not explain the striped pattern observed in the water content data. Instead, the striped pattern probably reflects the water usage of shallowly-rooted vegetation. At this site, "crop cover" of zorrow fescue grass was planted in every other row to reduce erosion and to decrease the near-surface soil water content to the optimal level for wine-grape production. The crop cover emerges in January and begins to go dormant in May. Although weeds and wild grasses grow in the rows without crop cover, the effects of the crop cover on near-surface water content are much more significant than the effects of incidental vegetation. The rows with crop cover had slightly lower mean water content values than the rows without crop cover during the dry months, but crop cover did not appear to significantly affect the soil water content when the near-surface soil was close to saturation in Jan. (Table 1). The influence of crop cover on near-surface water content also appears to be a function of depth, since rows with and without crop cover show greater differences in water content for the shallower $900 \mathrm{MHz}$ data than for the deeper $450 \mathrm{MHz}$ data.

The effects of crop cover on the near-surface water content variability at this site seem to be different from
Table 1 shows that the standard deviations of water content in rows with crop cover were less than those in rows without crop cover for all data sets except the $900 \mathrm{MHz}$ data collected in Jan. To explore the influence of crop cover on the spatial correlation of water content, separate experimental variograms were calculated for rows with and without crop cover. Experimental variograms for data acquired using both GPR frequencies in Sept. 2001 in rows with and without crop cover are shown Fig. 8. These variograms show that rows with crop cover had lower sills than rows without crop cover, but that crop cover affected the range differently for the $900 \mathrm{MHz}$ and $450 \mathrm{MHz}$ data. For the $900 \mathrm{MHz}$ data, the ranges with and without crop cover were 75 and $100 \mathrm{~m}$, respectively, while the $450 \mathrm{MHz}$ data showed a range of $95 \mathrm{~m}$ with crop cover and $60 \mathrm{~m}$ without. These variograms also indicate that the effects of crop cover are most significant on very shallow water content measurements $(900 \mathrm{MHz})$, as the differences between variograms calculated from rows with and without crop cover are much greater for the $900 \mathrm{MHz}$ data than for the deeper $450 \mathrm{MHz}$ data. Inspection of variograms calculated with and without crop cover for the other data sets shows that crop cover has the greatest effect on water content variability when the soil is dry and the fescue roots may be actively removing soil water from wetter zones, causing the near-surface soil to be more uniformly dry across the field. Data acquired in Jan. under nearly saturated conditions when the crop cover was emerging show only minor differences between rows with and without crop cover (Fig. 9), but water content variability is slightly higher in rows with crop cover for this data set. The slight increase in variability in rows with crop cover may be caused by variable transpiration of the newly emergent crop cover when the soil water content is high or by changes in water content caused by alteration of the soil structure as a result of new root growth.

The effects of vegetation on soil water content variability are probably determined by the state of vegetation and the mean soil moisture. For this site, even fairly dormant vegetation decreased the water content variability in shallow, dry soils. However, variability was slightly increased when the soil was wet and the vegetation was actively undergoing transpiration. This latter state may be more similar to the experiments performed by other researchers (Hupet and Vanclooster, 2002; De Lannoy et al., 2006) who attributed high water content variability to vegetation.

\section{Water Content Variability and Soil Texture}

Several researchers have shown that soil water content variability is partially controlled by the variability of effective soil properties (Or and Rubin, 1993; 


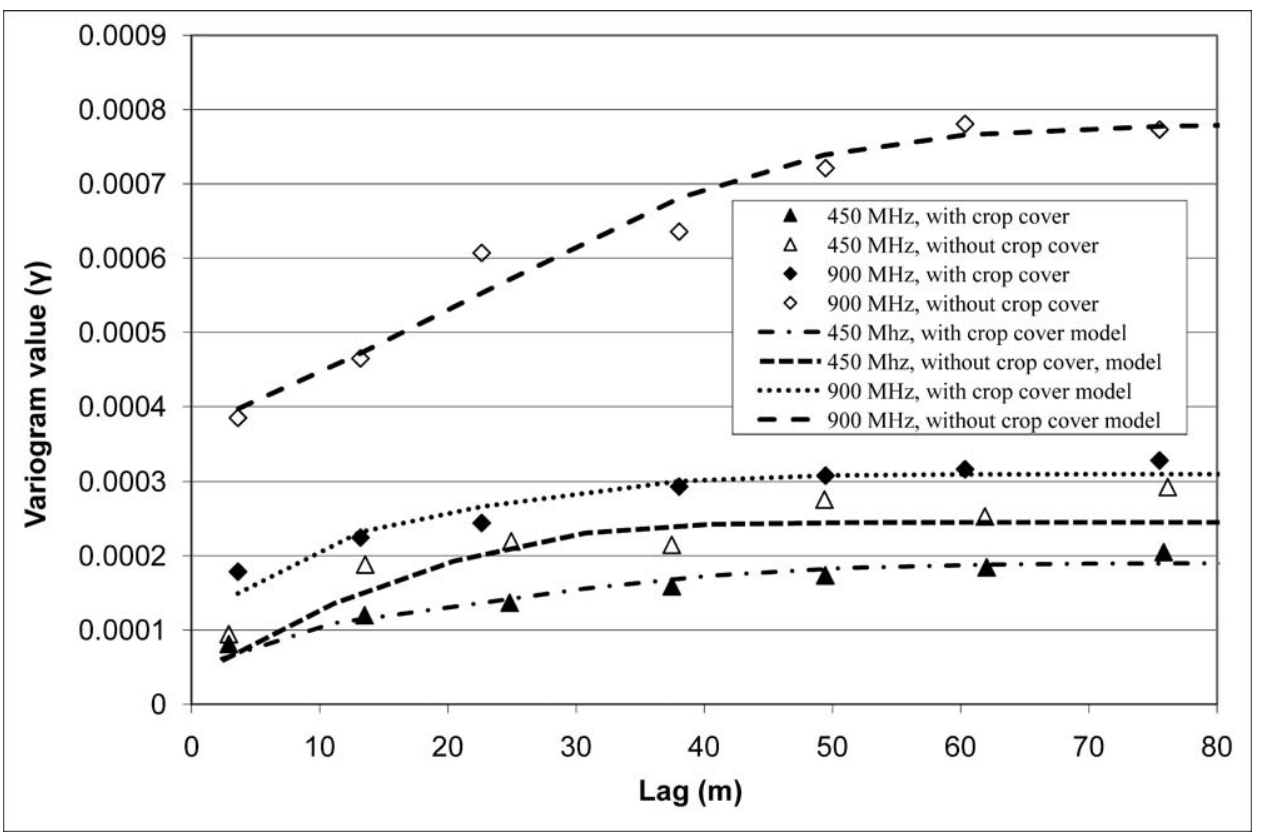

Figure 8. Experimental variograms of water content estimates from $450 \mathrm{MHz}$ and $900 \mathrm{MHz}$ GPR data acquired in Sept. 2001 for rows with and without crop cover.

Rubin and Or, 1993; Entekhabi and Rodriguez-Iturbe, 1994; Hupet and Vanclooster, 2002; Peters-Lidard and Pan, 2002; Ryu and Famiglietti, 2005; Teuling and Troch, 2005; De Lannoy et al., 2006; Famiglietti et al., 2008), but few studies have quantified the variability of soil texture. In this study, the influence of soil texture on near-surface soil water content variability was investigated by comparing experimental variograms for both parameters. Forty-seven soil samples were collected across the field, and the percents of sand, silt, and clay were determined for each sample. To analyze the soil texture variability, the soil texture was quantified as the percent sand in each sample. The percent sand was chosen to quantify soil texture as the GPR responses to silts and clays at this site were very similar, and no additional information was gained by considering silts

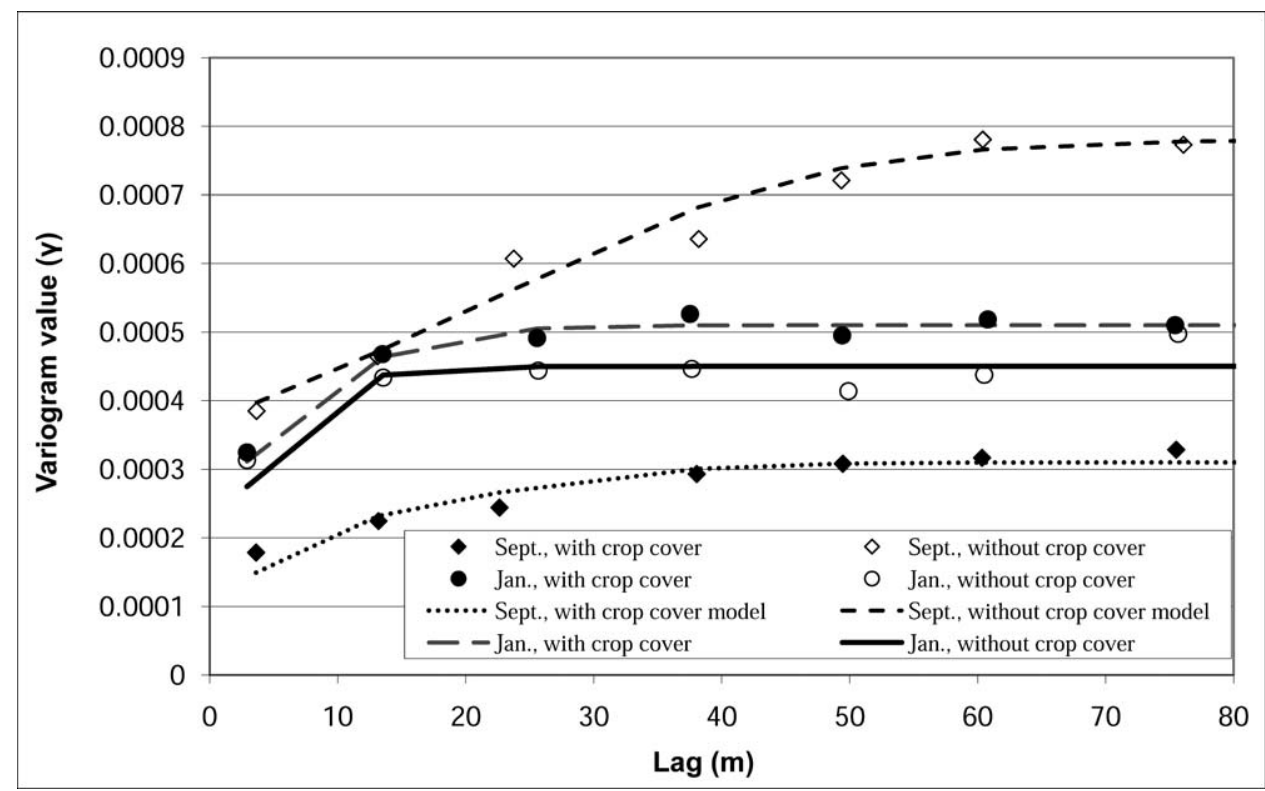

Figure 9. Experimental variograms of water content estimates from $900 \mathrm{MHz}$ GPR data acquired in Sept. 2001 and Jan. 2002 for rows with and without crop cover. 

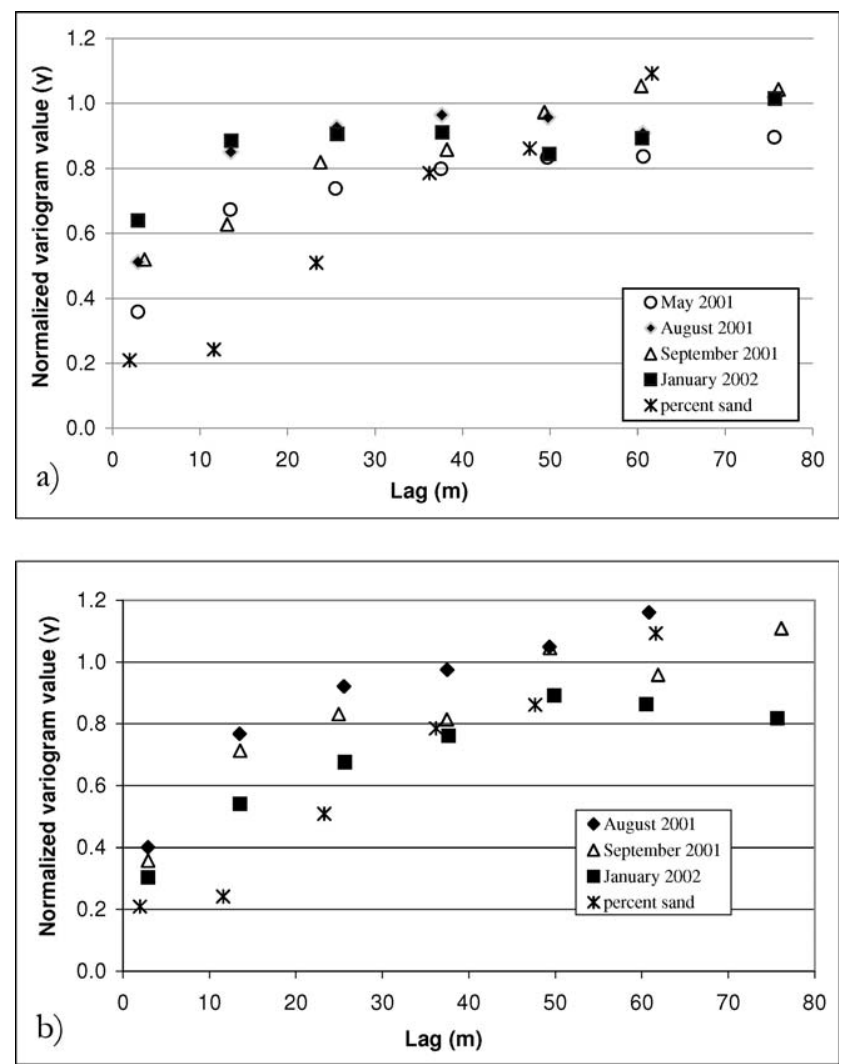

Figure 10. a) Normalized experimental variograms of water content from $900 \mathrm{MHz}$ GPR data acquired in rows without crop cover and of soil texture, where soil texture is quantified as the percent sand. Normalization was performed by dividing the variogram value by the variance of the data set. b) Normalized experimental variograms of water content from $450 \mathrm{MHz}$ GPR data acquired in rows without crop cover and of soil texture.

and clays separately. Thus, the soil could be divided into the coarse-grained fraction (sand) and the fine-grained fraction (silt and clay) without loss of information. To compare the spatial correlations of soil texture and water content, the experimental variograms were normalized by the variance for each data set (Fig. 10). The variograms of water content shown in Fig. 10 were calculated using only data acquired in rows without crop cover, since the influence of vegetation on nearsurface water content may obscure the relationship between soil texture and water content variability. Inspection of the variograms in Fig. 10 shows that soil texture has greater spatial correlation than water content for lags up to $\sim 35 \mathrm{~m}$. Also, the variogram model that best fits the experimental soil texture variogram is Gaussian, which has greater correlation at small lags than the exponential model which best describes the first portion of the water content variograms. The relatively low spatial correlation of water content in comparison to soil texture is especially apparent for the variograms generated from $900 \mathrm{MHz}$ data (Fig. 10(a)), indicating that shallow water content measurements are significantly influenced by factors other than soil texture, even at a site with no significant topography or changes in agricultural practices. The variograms calculated using water content estimates from $450 \mathrm{MHz}$ GPR data (Fig. 10(b)) are more similar to the soil texture variograms, especially for the data collected in Jan., when the soil was near saturation. These results indicate that deeper water content estimates may be more indicative of soil texture than very shallow measurements, and that the influence of soil texture on near-surface water content may be most significant when the soil is near saturation.

\section{Using Geophysical Measurements of Water Content to Supplement Soil Texture Measurements}

Geophysical techniques can be used to obtain a large number of water content estimates across a site, but soil texture measurements are typically more difficult to obtain. Measurements of soil texture usually involve collection of the soil sample followed by sieve analysis to determine the grain size distribution of the coarse-grained fraction of the soil. Further analysis using hydrometers or lasers to characterize the finegrained fraction of the soil is usually necessary. These techniques are time consuming, so soil texture is a relatively expensive parameter to characterize over a large area.

During this experiment, soil texture measurements were made in conjunction with gravimetric water content measurements at three times. The gravimetric water content measurements were converted to volumetric water content estimates, and the soil texture was quantified as percent sand, silt, and clay. Figure 11 shows that the coarse-grained fraction of the soil (percent sand) correlates reasonably well with volumetric water content, and the greatest correlation occurs when the soil is near saturation (Jan.). This correlation suggests that water content measurements might be used to improve soil texture estimation.

To determine if the geophysically-derived estimates of water content could be used to improve soil texture estimation, estimates of the coarse-grained soil fraction (CGSF) calculated using ordinary kriging of the CGSF and using co-kriging of the CGSF and water content were made. To better understand the dependence of water content on soil texture (without additional variables), only soil samples acquired in rows without crop cover were used in variogram and kriging calculations. Thirty-one soil samples were acquired in these rows (sample locations shown in Fig. 12(a)), and 


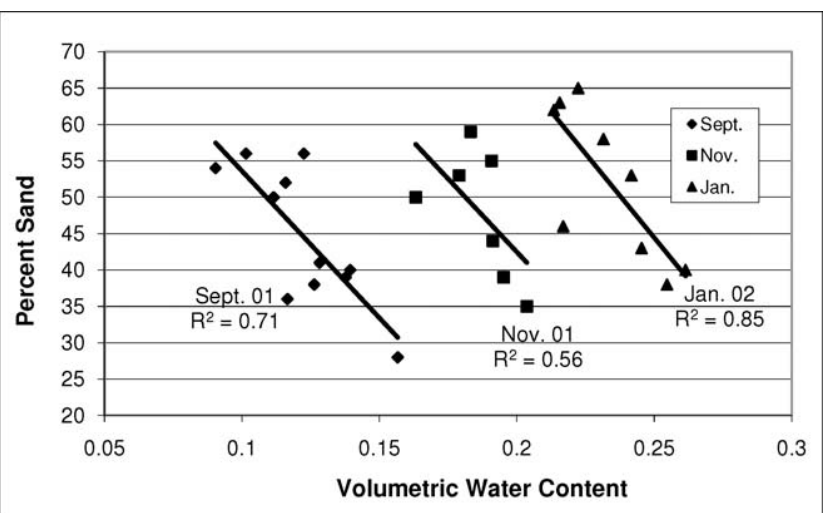

Figure 11. Correlations between volumetric water content estimates and soil texture measurements for three sampling campaigns.

these samples were used to calculate an experimental variogram and a variogram model using GS+software, which is a geostatistical analysis and mapping program. The variogram model was used to krige CGSF estimates across the site (Fig. 12(a)). Next, approximately half of the CGSF measurements were removed from the data file; the measurements removed were chosen so that the remaining measurements would offer the best possible spatial coverage of the field. Thus, when two samples were separated by only a small distance, one of the samples was removed. A new CGSF experimental variogram was calculated, and kriging was performed using the variogram model that best fit this new variogram. Figure 12(b) shows the CGSF estimates when kriging was performed using a subset of the soil texture measurements. Finally, a cross-variogram was calculated using the subset of CGSF measurements shown in Fig. 12(b) and the volumetric water content estimates from the $450 \mathrm{MHz}$ GPR data acquired in Jan. Co-kriging of these two data sets was performed, and the resulting CGSF estimates are shown in Fig. 12(c). This analysis was then repeated using only the subset of data points which were initially removed (those shown in Fig. 12(a) but not in Fig. 12(b)) as the sampling points; Fig. 13(a) shows the CGSF estimates from kriging the second subset of soil texture measurements, while Fig. 13(b) shows the CGSF estimates from cokriging this second soil texture subset with water content estimates.

Visual comparison of Figs. 12 and 13 shows that the CGSF maps developed using co-kriging with water content estimates (Figs. 12(c) and 13(b)) are significantly more similar to the map developed using all the CGSF measurements (Fig. 12(a)) than are the maps derived from only a subset of CGSF measurements (Figs. 12(b) and 13(a)). To quantify the improvement in CGSF estimation, the error of the kriged and co-kriged estimates was evaluated by comparing the CGSF values obtained from estimation to the measured values omitted from the estimation calculations. When compared to the measured CGSF values, the root mean squared error (RMSE) of the CGSF estimates derived from co-kriging water content and a subset of CGSF values was $10 \%$ and $6 \%$ for the first and second data subsets, respectively, while the RMSE of CGSF derived from kriging only a subset of CGSF values was $12 \%$ and $7 \%$ for the first and second subsets, respectively. Crossvalidation of the subset of CGSF measurements shown in Figs. 12 and 13 produced a RMSE of $6 \%$ and $7 \%$ for the first and second subsets, respectively, when cokriging of CGSF and soil water content was performed, and a RMSE of $12 \%$ and $8 \%$ for the first and second subsets, respectively, when only kriging of the CGSF was used. The relatively modest reduction in RMSE obtained by co-kriging CGSF and water content may indicate that geophysically-derived water content can only slightly improve soil texture estimation, but may also reflect the small number of CGSF data points and the methodology used to choose which points to omit. When the entire map area is considered (Fig. 12(a)), the co-kriging of soil texture and water content seems to significantly improve the accuracy of the soil texture estimates.

\section{Conclusions}

In this study, GPR groundwave techniques were used to generate very high-resolution estimates of nearsurface soil water content over a three acre field during four data acquisition campaigns. The large GPR data sets, combined with the flat topography and the uniform agricultural practices employed at this site, provided an unusual opportunity to study water content variability at the field scale as a function of measurement depth, season, vegetation, and soil texture. Geostatistical analyses showed that the spatial correlation changed with measurement depth, where shallow soils had greater variability than deeper soils. The higher variability in the shallower measurements may be caused by the heterogeneity of surficial processes such as precipitation and irrigation. Comparison of variograms of water content estimates acquired at different times under conditions of natural precipitation or evapotranspiration showed similar sills for dry and wet soil, but decreased correlation lengths in wet soils, which may reflect the heterogeneity of soil properties. Irrigation significantly increased the water content variability of very shallow soils, but did not notably affect deeper measurements. Shallowly-rooted vegetation such as crop cover reduced the mean water content and the variability of water content when the soil was dry and 

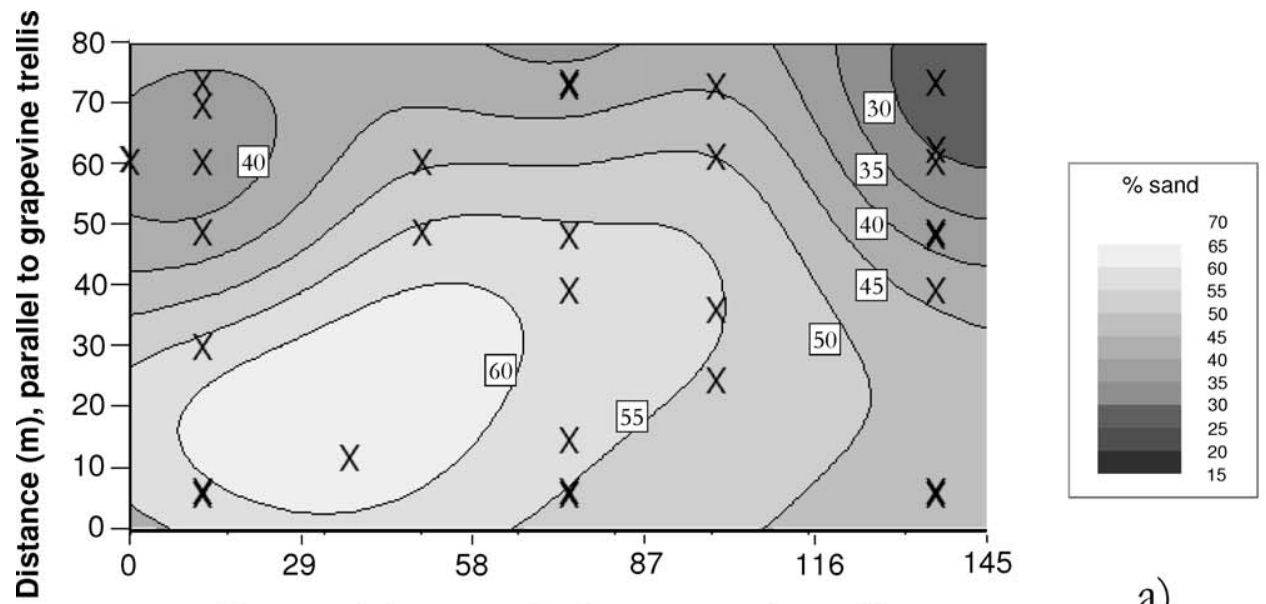

a)

Distance $(m)$, perpendicular to grapevine trellis

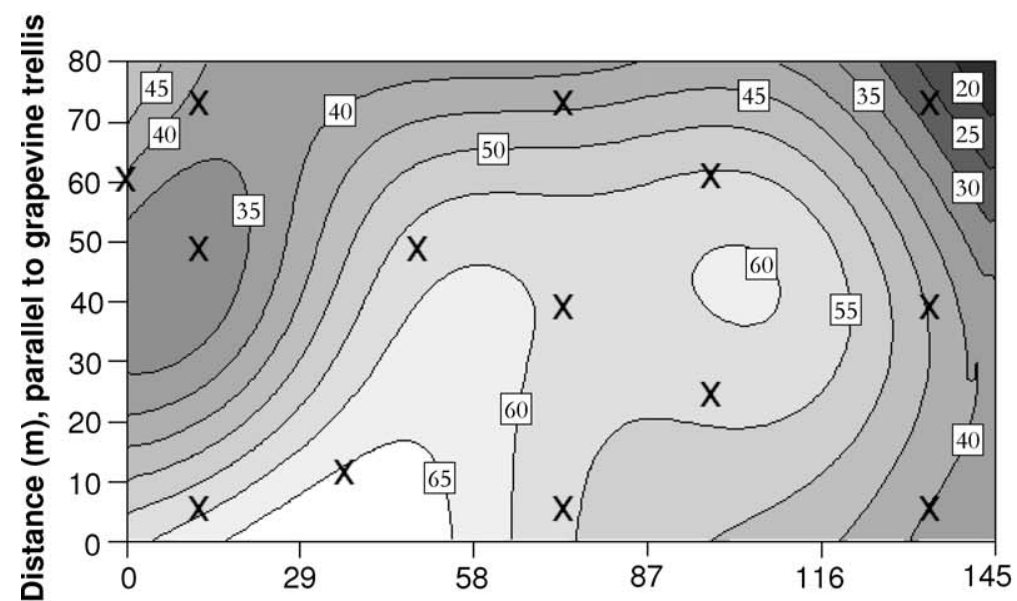

Distance $(\mathrm{m})$, perpendicular to grapevine trellis

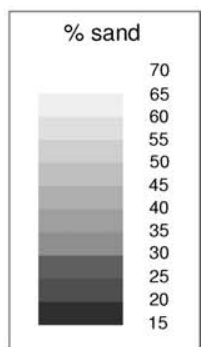

b)

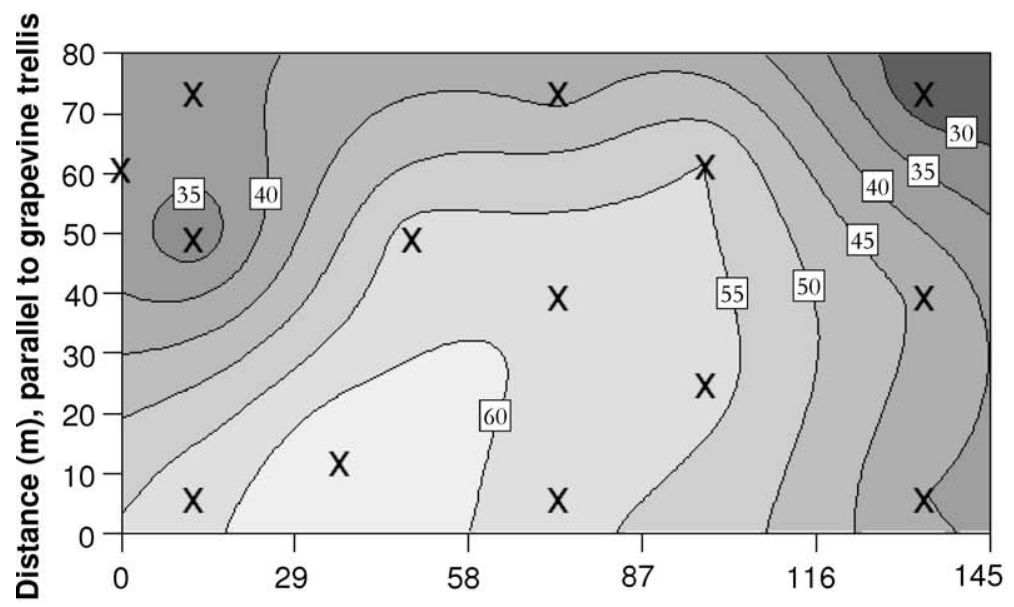

Distance $(m)$, perpendicular to grapevine trellis

Figure 12. a) Contour map of the percent sand in the uppermost $20 \mathrm{~cm}$ developed using kriging of all CGSF measurements in rows without crop cover. b) Contour map of the percent sand developed using kriging of a subset of CGSF measurements in rows without crop cover. c) Contour map of the percent sand developed using co-kriging of a subset of CGSF measurements in rows without crop cover and volumetric water content estimates from $450 \mathrm{MHz}$ GPR data acquired in Jan. 
characterizing the soil water content variability, GPR measurements of water content can be used in conjunction with soil texture measurements to better characterize the soil texture distribution across a site, which might be used to identify sites suitable for potential agricultural development and to guide the planning of new vineyards or orchards.

\section{Acknowledgments}

This project was supported by the National Research Initiative of the USDA Cooperative State Research, Education and Extension Service, grant number 2006-35107-17245 and by the University of Wisconsin-Eau Claire. We sincerely thank Daniel Bosch and the Robert Mondavi Winery for providing vineyard technical information and vineyard access as well as in-kind support. We also thank the many researchers who participated in our field acquisition campaigns.

\section{References}

Bell, K.R., Blanchard, B.J., Schugge, T.J., and Witczak, M.W., 1980, Analysis of surface moisture variations within large field sites: Water Resources Research, 16, 796-810.

Berktold, A., Wollny, K.G., and Alstetter, H., 1998, Subsurface moisture determination with the ground wave of GPR in Proceedings, GPR 98 Conference.

Bosch, D.D., Lakshmi, V., Jackson, T.J., Choi, M., and Jacobs, J.M., 2006, Large scale measurements of soil moisture for validation of remotely sensed data: Georgia soil moisture experiment of 2003: J. of Hydrology, 323, $120-137$.

Bouten, W., Heimovaara, T.J., and Tiktak, A., 1992, Spatial patterns of throughfall and soil water dynamics in a Douglas Fir stan: Water Resources Research, 28(12) 3227-3233.

Chanzy, A., Tarussov, A., Judge, A., and Bonn, F., 1996, Soil water content determination using digital groundpenetrating radar: Soil Science of America Journal, 60, $1318-1326$.

Davis, J.L., and Annan, A.P., 1989, Ground-penetrating radar for high-resolution mapping of soil and rock stratigraphy: Geophysical Prospecting, 37, 531-551.

De Lannoy, G.J.M., Verhoest, N.E.C., Houser, P.R., Gish, T.J., and van Meirvenne, M., 2006, Spatial and temporal characteristics of soil moisture in an intensively monitored agricultural field (OPE3): Journal of Hydrology, 331, 719-730.

Deutsch, C.V., and Journel, A.G., 1998, Geostatistical Software Library and User's Guide: Oxford University Press, Oxford.

Dry, P.R., Loveys, B.R., Stoll, M., Stewart, D., and McCarthy, M.G., 2000, Partial root zone drying an update, Aust.: Grapegrower and Winemaker, 438a, $35-39$.
Du, S., 1996, Determination of water content in the subsurface with the ground wave of ground penetrating radar Ph.D. thesis, Fakultät fiir Geowissenschaften der LudwigMaximilians-Universitat Miinchen, $117 \mathrm{pp}$.

Du, S., and Rummel, P., 1994, Reconnaissance studies of moisture in the subsurface with GPR in Proc. $5^{\text {th }}$ Int. Conf. Ground Penetrating Radar, Kitchener, Ontario, Canada, Vol. 3, Waterloo Centre for Groundwater Res., Univ. of Waterloo, ON, 1241-1248.

Entekhabi, D., and Rodriguez-Iturbe, I., 2004, Analytical framework for the characterization of the space-time variability of soil moisture: Adv. Water Resourc., 17, 35-45.

Fageria, N.K., 1992. Maximizing Crop Yields: Mercel Dekker, New York, 133-168.

Famiglietti, J.S., Rudnicki, J.W., and Rodell, M., 1998, Variability in surface moisture content along a hillslope transect: Rattlesnake Hill, Texas: J. of Hydrology, 210, 259-281.

Famiglietti, J.S., Devereaux, J.A., Laymon, C.A., Tsegaye, T., Houser, P.R., Jackson, T.J., Graham, S.T., Rodell, M., and van Oevelen, P.J., 1999, Ground-based investigation of soil moisture variability within remote sensing footprints during the Southern Great Plains 1997 (SGP97) Hydrology Experiment: Water Resources Research, 35(6) 1839-1851.

Famiglietti, J.S., Ryu, D., Berg, A.A., Rodell, M., and Jackson, T.J., 2008, Field observations of soil moisture variability across scales: Water Resources Research, 44, W01423, 2006WR005804.

Galagedara, L.W., Parkin, G.W., and Redman, J.D., 2003, An analysis of the ground-penetrating radar direct ground wave method for soil water content measurement: Hydrological Processes, 17, 3615-3628.

Galagedara, L.W., Parkin, G.W., and Redman, J.D., 2004, Measuring and modeling of GPR ground wave depth penetration under transient soil moisture conditions in Proc. $10^{\text {th }}$ Int. Conf. Ground Penetrating Radar, Delft, The Netherlands, 505-508.

Galagedara, L.W., Parkin, G.W., Redman, J.D., von Berktold, P., and Endres, A.L., 2005a, Field studies of the GPR ground wave method for estimating soil water content during irrigation and drainage: J. Hydrology, 301, 182-197.

Galagedara, L.W., Redman, J.D., Parking, G.W., Annan, A.P., and Endres, A.L., 2005b, Numerical modeling of GPR to determine the direct ground wave sampling depth: Vadose Zone Journal, 4, 1096-1106.

Gambolati, G., and Galeati, G., 1987, Comment on analysis of nonintrinsic spatial variability by residual kriging with application to regional groundwater levels: Mathematical Geology, 19, 249-257.

Grayson, R.B., Western, A.W., Chiew, F.H.S., and Blöschl, G., 1997, Preferred states in spatial soil moisture patterns: local and non-local controls: Water Resour. Res., 33(12) 2897-2908.

Grote, K., Hubbard, S., and Rubin, Y., 2003, Field-scale estimation of volumetric water content using GPR 
groundwave techniques: Water Resour. Res., 39(11) $1321-1334$.

Hillel, D., 1997. Environmental soil physics: Academic Press, New York.

Hubbard, S., Grote, K., and Rubin, Y., 2002, Estimation of near-subsurface water content using high frequency GPR ground waves: The Leading Edge, Society of Exploration Geophysics, 21(6) 552-559.

Hubbard, S., Lunt, I., Grote, K., and Rubin, Y., 2006, Vineyard soil water content: mapping small scale variability using ground penetrating radar in Macqueen, R.W., and Meinert, L.D. (eds.), Fine Wine and Terroir The Geoscience Perspective: Geoscience Canada Reprint Series Number 9, Geological Association of Canada, St. John's, Newfoundland, 193-202, ISBN 1897095-21-X; ISSN 0821-381X.

Huisman, J.A., Sperl, C., Bouten, W., and Berstraten, J.M., 2001, Soil water content measurements at different scales: accuracy of time domain reflectometry and ground penetrating radar: J. Hydrol., 245, 48-58.

Huisman, J.A., Hubbard, S., Redman, J.D., and Annan, A.P., 2003, Monitoring soil water content with groundpenetrating radar: A review: Vadose Zone Journal, 2, 476-491.

Hupet, F., and Vanclooster, M., 2002, Intraseasonal dynamics of soil moisture variability within a small agricultural maize cropped field: J. of Hydrology, 261, 86-101.

Lesmes, D., Herbstzuber, R.J., and Wertz, D., 1999, Terrain permittivity mapping: GPR measurements of nearsurface soil moisture in Proc. Symposium on the Application of Geophysics to Engineering and Environmental Problems, 575-582.

Or, D., and Rubin, Y., 1993, Stochastic modeling of unsaturated flow in heterogeneous media with water uptake by plant roots: tests of the parallel columns model under two-dimensional flow conditions: Water Resour. Res., 29(12) 4109-4119.

Owe, J., Jones, E.B., and Schmugge, T.J., 1982, Soil moisture variation patterns observed in Hand County, South Dakota: Water Resources. Bull., 18, 949-954.

Peters-Lidard, C.D., and Pan, F., 2002, Re-thinking the contradictions of soil moisture spatial variability in Eos. Trans. AGY, 83(47), Fall Meet. Suppl. Abstract NG12C-1042.

Petrone, R.M., Price, J.S., Carey, S.K., and Waddington, J.M., 2004, Statistical characterization of the spatial variability of soil moisture in a cutover peatland: Hydrol. Process., 18, 41-52.

Rangeley, W.R., 1987, Irrigation and drainage in the world in Water and Water Policy in the World, Jordan, W.R. (ed.), Texas A\&M University, College Station.

Roth, K., Schulin, R., Fluhler, H., and Attinger, W., 1990, Calibration of time domain reflectometry for water content using a composite dielectric approach: Water Resour. Res., 26(10) 2267-2273.

Rubin, Y., 2003. Applied Stochastic Hydrogeology: Oxford University Press.

Rubin, Y., and Or, D., Stochastic modeling of unsaturated flow in heterogeneous soils with water uptake by plant roots: the parallel columns model: Water Resour. Res., 29(3) 619-631.

Ryu, D., and Famiglietti, J.S., 2005, Characterization of footprint-scale surface soil moisture variability using Gaussian and beta distribution functions during the Southern Great Plains 1997 (SGP97) hydrology experiment: Water Resour. Res., 41, W12433, doi:10.1029/ 2004WR003835.

Sperl, C., 1999, Determination of spatial and temporal variations of the soil water content in an agro-ecosystem with ground penetrating radar (In German) Ph.D. thesis, Technische Univeritat München, Munich, Germany.

Teuling, A.J., and Troch, P.A., 2005, Improved understanding of soil moisture variability dynamics: Geophy. Res. Lett., 32, L05404, doi:10.1029/2004GL021935.

Topp, G.C., Davis, J.L., and Annan, A.P., 1980, Electromagnetic determination of soil water content: measurements in coaxial transmission lines: Water Resour. Res., 16(3) 574-582.

Topp, G.C., Watt, M., and Hayhoe, H.N., 1996, Point specific measurement and monitoring of soil water content with an emphasis on TDR: Canadian Journal of Soil Science, 76(3) 307-316.

Van Overmeeren, R., Sariowan, S., and Gehrels, J., 1997, Ground penetrating radar for determining volumetric soil water content; results of comparative measurements at two test sites: J. Hydrol., 197, 316-338.

Van Wijk, a.L.M., 1988, Predictions of workability and emergence date in dependence on soil and drainage conditions Institute for land and water management research, Wageningen (The Netherlands), 1-5.

Vischel, T., Pegram, G.G.S., Sinclair, S., Wagner, W., and Bartsch, A., 2008, Comparison of soil moistuer fields estimated by catchment modeling and remote sensing: a case study in south Africa: Hydrol. Earth Syst. Sci., 12, 751-767.

Western, A.W., Bloschl, G., and Grayson, R.B., 1998, Geostatistical characterization of soil moisture patterns in the Tarrawara catchment: J. Hydrol., 205, 20-37.

Western, A.W., and Blöschl, G., 1999, On the spatial scaling of soil moisture: J. Hydrol., 217, 203-224.

Williams, L.E., and Matthews, M.A., 1990, Grapevine in Irrigation of Agricultural Crops - Agronomy Monograph, 30, 1019-1055, Stewart, B.A., and Nielsen, D.R. (eds.), ASA-CSAA-SSSA, Madison, WI.

Wilson, D.J., Western, A.W., and Grayson, R.B., 2004, Identifying and quantifying sources of variability in temporal and spatial soil moisture observations: Water Resour. Res., 40, W02507, doi:10.1029/2003WR002306.

\section{APPENDIX A}

A variogram model was fit to each experimental variogram using least squares regression techniques. A linear combination of an exponential and Gaussian model seemed to best fit the experimental variograms, so this combination was used to determine variogram model parameters. Table 2 gives the model parameters 
for each variogram. The exponential model is defined as:

$$
\gamma(h)=c\left(1-\exp \left(-\frac{h}{l}\right)\right),
$$

where $c$ is the sill and $l$ is the correlation length. For the exponential model, the range is $\approx 3 l$. The Gaussian model is defined as:

$$
\gamma(h)=c\left(1-\exp \left(-\frac{h^{2}}{l^{2}}\right)\right),
$$

where the range is $\approx 7 l / 4$. 